\title{
Dimensionless Index
}

National Cancer Institute

\section{Source}

National Cancer Institute. Dimensionless Index. NCI Thesaurus. Code C147148.

The ratio of the left ventricular outflow tract (LVOT) velocity to the maximum velocity of the aortic valve. 